\title{
Inventory Decision Model of Two-echelon Repairable Spares
}

\author{
Guo Feng, Diao Jun, Wang Hengxin, Guo Xingxiang \\ Naval Aeronautical and Astronautical University Qingdao Branch, Qingdao 266041, China \\ Email:gf536149@163.com
}

\begin{abstract}
Illustrated the necessity to solve the problem of twoechelon inventory between the rear inventory and base by the system methods. Replaced the largest availability with the least shortfall as the objective function, took the total prices not greater than the total support cost as the constraint condition, established the two-echelon spares inventory decision model. Solved it with the marginal analysis method, compiled the arithmetic, and applied the model and its arithmetic to a example, carried out the numerical experiments and theoretical analysis, calculated it with Matlab. The results prove that the optimal effectiveness and practicability of the model is very well.
\end{abstract}

Keywords-Two-echelon spares, Inventory decision model, Availability, Shortage

\section{INTRODUCTION}

With the rapid development of high-tech equipments, spares management used to make equipments normally used attracts more and more attention. Equipments are more and more complex, price of spares sharply rise, if it continues to stay alone in the traditional management methods based on experience, the conflict between lack of funds and shortage of spares will only become more prominent, the situation may even be unsustainable [1]. This requires modeling through quantitative methods to optimize inventory to address the optimal cost-effectiveness between the equipment availability and spares protection funds [2].

Repairable parts generally have higher prices and low stocks in the equipment protection work, whose security work are much more complicated than consumable parts. Therefore, inventory modeling of repairable parts become an important issue in the equipment support researches developed by countries. Optimization algorithm is to weigh the stocks of spares between the rear warehouse and bases supplied by it, which is the optimal inventory problem of the two-echelon supply model, and can be solved by system approach.

System approach is to regard the equipments of all bases as a large system, and to study the rational allocation of the stock between the rear warehouse and bases, so that the equipments availability of the large system, rather than a single base, reaches maximum and supply costs minimum. Therefore, system approach can be gradually identified the program of the reserve decision of a large number of spares, both meeting the requirements for the equipment availability, without breaking the budget limit.

\section{INVENTORY BALANCE EQUATION}

Assuming a failed unit of a spare in a base can be repaired within a certain time, and be expressed by mean of the probability distribution as $\mathrm{T}$; At the same time, always assuming that the base can repair the spares, there are inventory balance equation [3]

$$
s=\mathrm{OH}+\mathrm{DI}-\mathrm{BO}
$$

Where, $\mathrm{s}$ is the stocks, $\mathrm{OH}$ is the existing number of stock in the base, DI is the number of repairing spares, BO is the spares shortage. As the price of repairable spares is high, demand is low, so assume that the economic order quantity $\mathrm{Q}$ is equal to 1 . Inventory balance equation is the fundamental basis to make the inventory decisions, is the key to establish the inventory decision model.

\section{INVENTORY DECISION MODEL}

Inventory decision model is used to calculate the optimal allocation of spares inventory between the rear warehouse and bases to make the equipment availability highest. And under the conditions of no cannibalizatioin, to find the minimum number of shortage is equivalent to find the maximum equipment availability. Spares shortage is a supply efficient indicator [4-5], and facilitate the calculation, so minimizing total shortage in the bases can be acted as the objective function of the inventory decision.

In addition, the repairable spares in the bases is many, the total shortage is the accumulation of the separable shortage function of spares, so the research may focus on a spare at the same time, while the model is simplified to optimally allocate the stocks of spares between the rear warehouse and bases, so that the total shortfall of the spare reaches minimum; the constraint condition is that the total value of the spare stocks between the rear warehouse and bases is not greater than the total supply costs, then the model is

$$
\left.\begin{array}{l}
\min z=\sum_{j=1}^{J} \operatorname{EBO}\left(s_{j}\right) \\
c \sum_{j=1}^{N} s_{j} \leq C
\end{array}\right\}
$$

Where, $\mathrm{c}$ is the unit price of spares, $\mathrm{C}$ is the total supply costs for spares, $\mathrm{sj}$ is the stocks of the jth base, $\mathrm{J}$ is the number of bases. $\mathrm{EBO}(\mathrm{sj})$ is the shortage of the jth base with the stocks as sj. The shortage model is 


$$
\operatorname{EBO}(s)=\sum_{x=s+1}^{\infty}(x-s) \operatorname{Pr}\{\mathrm{DI}=x\}
$$

Where, $\operatorname{Pr}\{\}$ is the probability distribution of the number of the repairing spares. According to Palm theorem, assume that demand any spare follows the Poisson process with the mean of annual average demand as $\mathrm{m}$, and the repair time of each failed unit are independent, and subject to the same distribution with annual average repair time as $\mathrm{T}$ years, then steady-state probability distribution of the number of repairing spares follows the Poisson distribution with mean as $\mu=\mathrm{mT}[6]$, namely

$$
\operatorname{Pr}(x)=\frac{\mu^{x} e^{-\mu}}{x !} \quad x=0,1,2,3, \ldots
$$

\section{MODEL SOLUTION}

The variable of some spare are defined as follows:

$\mathrm{mj}=$ the annual average demand of the jth base;

$\mathrm{T} j=$ the annual average repair time of the jth base;

$\mu \mathrm{j}=$ the average number of the pipeline;

$\mathrm{rj}=$ the repair probability of the $\mathrm{jth}$ base;

$\mathrm{O} \mathrm{j}=$ the average time from the application (order) to delivery between the rear warehouse and the jth base;

$\mathrm{sj}=$ the stocks of the jth base;

$\mathrm{Nj}=$ the number of airplanes in the jth base;

$\mathrm{Zj}=$ the number of the spare installed on single airplane in the jth base

The variable subscript $\mathrm{j}$ as 0 expresses the rear warehouse, as positive number expresses the number of different bases.

Solution algorithm is:

(1) Assume the stocks of the rear warehouse as $\mathrm{s} 0=\mathrm{p}$, then the algorithm starts from $p$ to 0 .

(2) Calculate the average number $\mu \mathrm{j}$ of the pipeline, namely

$\mu_{p j}=m_{j}\left(r_{j} T_{j}+\left(1-r_{j}\right)\left\{O_{j}+\frac{\left.\operatorname{EBO}_{0} \mid m_{0} T_{0}\right]}{m_{0}}\right\}\right) \quad j>0, s_{0}=p$

Where, $\mathrm{m} 0$ is the annual average demand of the rear warehouse, which is sum of spares not repaired in the bases, that is

$$
m_{0}=\sum_{j=1}^{J} m_{j}\left(1-r_{j}\right)
$$

(3) Calculated the expectation shortage EBO (sj) $\mid \mathrm{p}$ and marginal shortage $\triangle \mathrm{EBO}(\mathrm{sj}) \mid \mathrm{p}$ when the current stocks of the rear warehouse is $p$, and the marginal shortage is the first difference of the shortage, namely

$$
\left.\Delta \operatorname{EBO}\left(s_{j}\right)\right|_{p}=\left.\operatorname{EBO}\left(s_{j}-1\right)\right|_{p}-\left.\operatorname{EBO}\left(s_{j}\right)\right|_{p}
$$

In fact, generally use the marginal performance of the shortage to make the marginal analysis, which is the ratio of the first difference and unit price. However, because only one spare needs to be analyzed at the same time in the inventory decision model, and the price of the spare is same, so in the process of marginal analysis, the first difference of the shortage needs not be divided by the unit price. The method allocating the spares to the bases is: Make the configuration in turn according to their number, configure one every time, when to the last base, then start repeatedly from the first.

(4) Use the marginal analysis method [7-8] to calculate the total shortage Rpk when the current stocks of the rear warehouse is $\mathrm{p}$ and the total stocks $\mathrm{k}$ is from 0 to $\mathrm{K}$, namely

$$
\begin{aligned}
& R_{p 0}=\left.\sum_{j=1}^{J} \operatorname{EBO}\left(s_{j}\right)\right|_{p, s_{j}=0} \\
& R_{p k}=R_{p(k-1)}-\left.\Delta \operatorname{EBO}\left(s_{j}\right)\right|_{p, s_{j}=i} \\
& \left.\begin{array}{l}
i=\left[\frac{k}{J}\right]+1, j=k-i J, \\
k=1,2, \ldots \ldots, K-p, p=0,1, \ldots \ldots, K
\end{array}\right\}
\end{aligned}
$$

Where, $\mathrm{K}$ is the integer between $\mathrm{J}$ and $2 \mathrm{~J}$, which should make the total shortage minimum.

(5) The rear warehouse stocks $p$ increase one, if $p=K$, enter step 6, otherwise, enter Step 2.

(6) Solve $(\mathrm{K}+1)$ sets of total shortage minimum rq(such as equation (9) below) of all bases when the total stocks of the rear warehouse and bases is equal to $q(q \in[0, K])$, and the total stocks $\mathrm{k}$ of all bases, and the stocks (q-k) of the rear warehouse.

$r_{q}=\min \left\{R_{p k} \mid p+k=q, p=0,1, \ldots \ldots, K\right\}$

(7) Make the marginal analysis for rq to calculate the marginal shortage $\triangle \mathrm{rq}$, namely

$\Delta r_{q}=r_{q-1}-r_{q} \quad q=1, \ldots \ldots, K$

Then, calculate the allocation number of spares according to the total funding, and determine the optimal solution. Note: If the shortage function of the spares is not convex function, the application of the marginal analysis method does not necessarily get the optimal solution[9]. The solution is to discard all the non-convex points in the $\triangle$ rq to change the shortage function into the convex function.

(8) Calculate the equipment availability

The equipment availability $\mathrm{Aj}$ of the $\mathrm{jth}$ base is the expectation of the percentage of the number of airplane grounded not due to any backorder, its mathematical model is

$A_{j}=100\left\{1-\frac{\operatorname{EBO}\left(s_{j}\right)}{N_{j} Z_{j}}\right\}^{z_{j}}$

The total equipment availability A of all bases is the percentage of good airplanes in all bases, its mathematical model is

$$
A=\frac{\sum_{j=1}^{J} A_{j} N_{j}}{\sum_{j=1}^{J} N_{j}}
$$




\section{EXAMPLE}

The rear warehouse supplies five bases, there are 24 airplanes in each base. The number of some spare installed on single airplane is 1 , its unit price is 10,000 dollars, and total supply funds is 70,000 dollars. The relevant statistical data of the spare is shown in Table.1.

First, according to equation (2) (10), program with the Matlab to calculate the total shortage and marginal shortage and inventory configuration of the spare in the bases, indicating the convexity of the marginal shortage with "*”, as shown in Table.2.

Conclude that the total stocks of the spare is 7 from its total supply funds and unit price, table 2 shows that it belongs to the bump data, so the optimal solution is: The total shortage is 0.5670 , the total stocks is 7 , the stocks of every base is 1 .

Second, calculate the shortage expectations under the conditions of the optimal configuration plan, namely $[0.0692$, $0.0267,0.0915,0.0267,0.1271]$, and by which and equation (11) (12) conclude the total equipment availability of the bases, namely $99.72 \%$.

\section{SUMMARIES}

(1) It is needful to seek the optimal inventory configuration plan of an item of spare based on the overall efficiency of the equipment system, which can meet the equipment availability standard formulated by the decisionmaking department, and meanwhile make the supply funds minimum.

(2) If there are several spares, the spares have to repeat the above analysis, and then take advantage of marginal analysis to seek the optimal configuration program ${ }^{[10]}$.

\section{REFERENCES}

[1] FAN Qing-he; LI Ben-wei; HAO Da-qi. Study on model of optimization support reliability-based aeronautical material follow up spares[J].Journal of Naval Aeronautical Engineering Institute, 2006,21(1):113-116.(in chinese)

[2] ZHANG Heng; HUA Xing-lai; XU Shao-mu. Simulation optimization model of inventory decision for repairable spares systems[J]. Systems Engineering and Electronics, 2009, 31(6):1510-1514.(in chinese)

[3] Craig C. Sherbrooke. Optimal Inventory Modeling of Systems: MultiEchelon Techniques, Second Edition[M]. He Bujie, Translate. Beijing: Publishing House of Electronics Industry, 2008.

[4] LU Si-hai; ZHENG Jin-zhong; JI Ming. The analysis of the performance indicator of aircraft-spares support based on arinc model[J]. Warehouse Management and Technology, 2007(4):2931.(in chinese)

[5] ZHENG Jin-zhong; LU Si-hai; LI You-hu. Evaluation of Air Materials Support Effectiveness Based on utility Function[J]. Logistics Technology, 2007, 26(8):246-248.(in chinese)

[6] MA Bao-guo; ZHANG Ji-qiang; LIU Chang-xin. The Stock Decision of Repairable Air Material under Compound Poisson Demand[J]. Chinese Journal of Management Science, 2004, 12(Special Issue):177-180. (in chinese)

[7] LUO Bing; HU Qi-jun; YIN Di. How to Calculate the Supplied Amount of Spares Based on Marginal Cost[J]. Logistics Technology, 2009, 28(10):146-148. (in chinese)

[8] ZHANG Rui-chang; Zhao Song-zheng. Study to Optimize and Distribute the Cost of Air Spares Support[J]. Journal of Beijing University of Aeronautics and Astronautics, 2005, 31(1):102-104.(in chinese)

[9] U Dinesh Kumar. Reliability,Maintenance and Logistic Support A Life Cycle Approach[M]. LIU Qing-hua, SONG Ning-zhe, Translate. BeiJing: Publishing House of Electronics Industry, 2010:177-180.(in chinese)

[10] GUO Feng; LIU Chen-yu; LI Yuan-lei. Optimal Invention Research of Repairable Apares Based on Marginal Anaysis Method[J]. Value Engineering, 2010,29(5):95-96.(in chinese) 
TABLE I. THE STATISTICAL DATA OF SOME SPARE

\begin{tabular}{|c|c|c|c|c|}
\hline $\boldsymbol{j}$ & $\boldsymbol{m}_{\boldsymbol{j}}$ & $\boldsymbol{T}_{\boldsymbol{i}}$ & $\boldsymbol{r}_{\boldsymbol{j}}$ & $\boldsymbol{O}_{\boldsymbol{i}}$ \\
\hline 1 & 22 & 0.01 & 0.2 & 0.02 \\
\hline 2 & 24 & 0.01 & 0.25 & 0.01 \\
\hline 3 & 23 & 0.02 & 0.2 & 0.02 \\
\hline 4 & 24 & 0.01 & 0.3 & 0.01 \\
\hline 5 & 25 & 0.04 & 0.4 & 0.01 \\
\hline
\end{tabular}

TABLE II. OPTIMAL EXPECTED SHORTFALL

\begin{tabular}{|c|c|c|c|c|c|}
\hline$q$ & $p$ & $k$ & $\left.\mathbf{E B O}\left(s_{j}\right)\right|_{p}$ & $\left.\triangle \mathbf{E B O}\left(s_{j}\right)\right|_{p}$ & \\
\hline 0 & 0 & 0 & 4.0576 & 0.8860 \\
\hline 1 & 1 & 0 & 3.1716 & 0.6385 \\
\hline 2 & 2 & 0 & 2.5331 & 0.4107 \\
\hline 3 & 2 & 1 & 2.1225 & 0.3540 \\
\hline 4 & 1 & 3 & 1.7684 & 0.4759 \\
\hline 5 & 0 & 5 & 1.2926 & 0.4518 \\
\hline 6 & 1 & 5 & 0.8408 & 0.2739 \\
\hline 7 & 2 & 5 & 0.5670 & $*$ \\
\hline
\end{tabular}

